\title{
Isquemia Mesentérica Crónica - Um desafio diagnóstico
}

\author{
Chronic Mesenteric Ischaemia - A diagnostic challenge
}

Homem de 69 anos de idade, hipertenso e fumador (100 Unidades Maço Ano), internado para estudo de quadro com 6 meses de evolução de dor abdominal pósprandial, sem outros factores de agravamento ou de alívio, associada a anorexia, "medo de comer", náuseas, enfartamento e diarreia fétida, sem muco ou sangue e acompanhada de deterioração do estado geral (perda ponderal 16\% em 2 meses). Apesar de multiconsultado e de vários exames complementares, que incluíram estudo endoscópico alto e baixo e Tomografia Axial Computorizada abdomino-pélvica, permanecia sem diagnóstico. Pela suspeita de isquemia mesentérica crónica (IMC), realizou Angio-Tomografia-Computorizada (Figura 1 e 2), e posteriormente Angiografia, que demonstraram uma variante anatómica da artéria mesentérica superior proveniente do tronco celíaco, estenose osteal do tronco celíaco-mesentérico com compromisso hemodinâmico significativo e oclusão da artéria mesentérica inferior e respectiva circulação colateral exuberante.

A IMC é considerada uma entidade rara, constituindo menos de $5 \%$ da doença isquémica intestinal, sendo a doença aterosclerótica a causa mais comum ${ }^{1}$. A maioria dos doentes apresenta-se com sintomatologia abdominal arrastada, com agravamento progressivo, sendo submetidos a um estudo extensivo sem diagnóstico definitivo ${ }^{1}$. Este baseia-se numa história clínica detalhada apoiada com os meios auxiliares de diagnóstico que permitem o estudo das artérias gastrointestinais ${ }^{1}$. A angiografia continua a ser 0 exame gold standard de avaliação das artérias gastrointestinais. As principais desvantagens são o facto de ser um método invasivo e não permitir a visualização dos tecidos adjacentes. Outros métodos não invasivos permitem, com excelente sensibilidade e especificidade, a avaliação de estenose das artérias gastrointestinais e circulação colateral, dos quais se destacam a AngioTC e a AngioRM, que ainda permitem a visualização dos tecidos circundantes ${ }^{1}$. Não existem estudos que comparem estes dois métodos entre si, mas análises mostram que a AngioRM sobrevaloriza $15 \%$ das estenoses (quando comparada com a angiografia), e parece haver vantagem naAngioTAC pela alta resolução e a rapidez de aquisição de imagens ${ }^{1,2}$. 0 objectivo terapêutico principal é a revascularização da(s) artéria(s), o que pode ser conseguido por cirurgia de revascularização ou por angioplastia endovascular percutânea, com ou sem implantação de stent. Há quem defenda o tratamento cirúrgico como primeira linha para pacientes jovens e sem comorbilidades significativas, dado 0 maior risco de recorrência de sintomas no tratamento endovascular por re-estenose ( $28 \%$ vs $7-14 \%$ ). A verdade é que a taxa de sucesso a longo prazo e as complicações são semelhantes e a opção terapêutica deve ser discutida caso a caso mediante 0 perfil clínico do doente em causa ${ }^{1}$.

No caso do nosso doente, atendendo ao seu perfil de risco cardiovascular e à história clínica detalhada, levantou-se a suspeita clínica que foi confirmada com os exames complementares adequados. Na ausência de comorbilidades significativas e dado a extensão das lesões optou-se por um tratamento cirúrgico, com realização de bypass aorto-mesentérico com colocação de prótese (Figura 3), que decorreu sem complicações, com alívio sintomático total e sem recorrência após um ano de follow-up.

\section{Bibliografía}

1. Mensink PBF, Moons LMG, Kuipers EJ. Chronic gastrointestinal ischaemia: shifting paradigms. Gut 2011; 60:722-37.

2. Shih MC, Hagspiel KD. CTA and MRA in mesenteric ischaemia:part1, Role in diagnosis and differential diagnosis. AJR Am J Roentgenol 2007; 188:452-61.

\section{Diagnóstico}

Isquemia Mesentérica Crónica

\section{Rute M. Ferreira ${ }^{1}$, Alexandra Canedo ${ }^{2}$}

${ }^{1}$ Serviço de Medicina Interna, ${ }^{2}$ Serviço de Cirurgia Vascular.

Hospital da Arrábida, Grupo Espírito Santo Saúde. Vila Nova de Gaia. Portugal

Como citar este artículo: Ferreira RM, Canedo $A$.

Isquemia Mesentérica Crónica. Galicia Clin 2013; 74 (4): 195

Recibido: 10/4/2013; Aceptado: 31/7/2013
Figura 1. AngioTC com estenose de alto grau da emergência do tronco celíaco-mesentérico (seta)

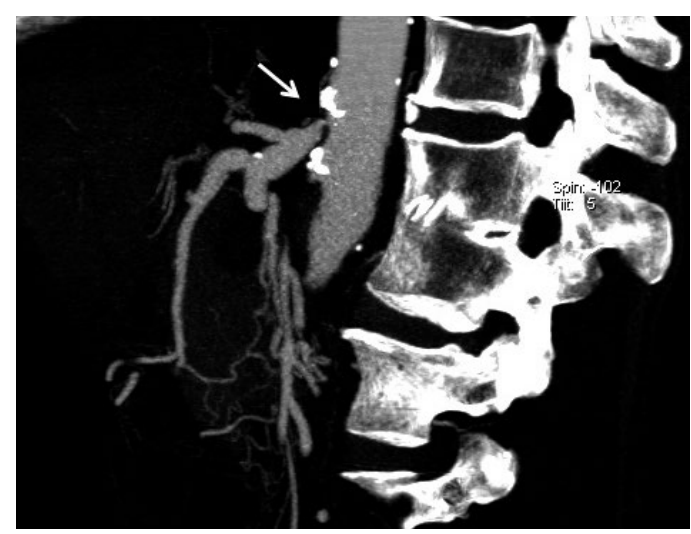

Figura 2. AngioTC com reconstrução arterial em que observa estenose do tronco celíaco-mesentérico (seta), variante do normal, com dilatação a jusante

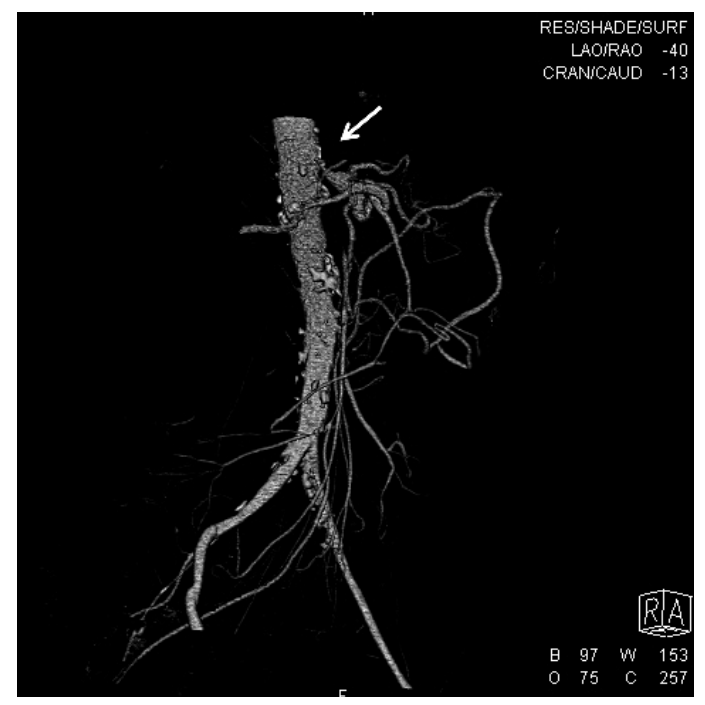

Figura 3. Esquema da cirurgia com colocação de prótese aorto-mesentérica

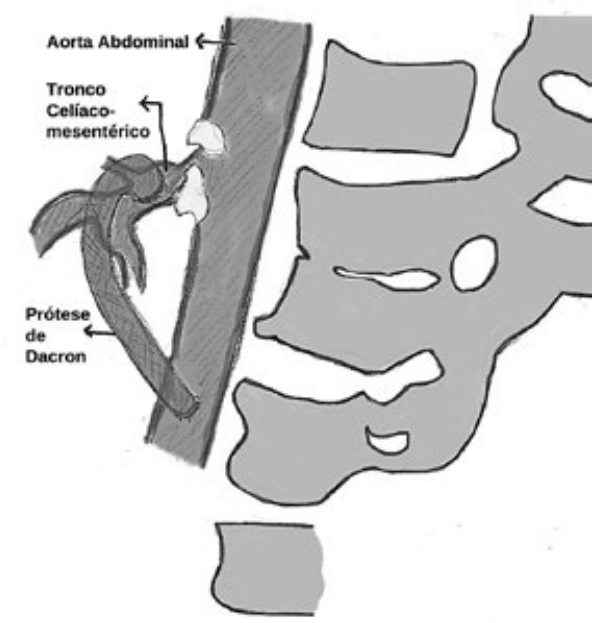

